\title{
Correction to: Cohomological tautness of singular Riemannian foliations
}

\author{
José Ignacio Royo Prieto ${ }^{1}$ (D) Martintxo Saralegi-Aranguren ${ }^{2} \cdot$ Robert Wolak $^{3}$
}

Published online: 6 February 2019

(c) The Author(s) 2019

\section{Correction to: RACSAM https://doi.org/10.1007/s13398-018-0597-6}

The original version of this article was revised due to a retrospective Open Access order.

The article Cohomological tautness of singular Riemannian foliations, written by José Ignacio Royo Prieto, Martintxo Saralegi-Aranguren, Robert Wolak, was originally published electronically on the publisher's internet portal (currently SpringerLink) on 16 November 2018 without open access.

With the author(s)' decision to opt for Open Choice the copyright of the article changed on 31 December 2018 to (C) The Author(s) 2018 and the article is forthwith distributed under the terms of the Creative Commons Attribution 4.0 International License (http:// creativecommons.org/licenses/by/4.0/), which permits use, duplication, adaptation, distribution and reproduction in any medium or format, as long as you give appropriate credit to the original author(s) and the source, provide a link to the Creative Commons license and indicate if changes were made.

Open Access This article is distributed under the terms of the Creative Commons Attribution 4.0 International License (http://creativecommons.org/licenses/by/4.0/), which permits unrestricted use, distribution, and reproduction in any medium, provided you give appropriate credit to the original author(s) and the source, provide a link to the Creative Commons license, and indicate if changes were made.

The original article can be found online at https://doi.org/10.1007/s13398-018-0597-6.

José Ignacio Royo Prieto

joseignacio.royo@ehu.eus

Martintxo Saralegi-Aranguren

saralegi@euler.univ-artois.fr

Robert Wolak

robert.wolak@im.uj.edu.pl

1 Department of Applied Mathematics, University of the Basque Country UPV/EHU, Pza. Ingeniero Torres Quevedo n. 1, 48013 Bilbao, Spain

2 Fèdèration CNRS, Nord-Pas-de-Calais FR 2956, UPRES-EA 2462 LML, Faculté Jean Perrin, Université d'Artois, Rue Jean Souvraz SP 18, 62307 Lens Cedex, France

3 Instytut Matematyki, Uniwersytet Jagiellonski, ul. Prof. Stanisława Łojasiewicza 6, 30-348 Kraków, Poland 
Publisher's Note Springer Nature remains neutral with regard to jurisdictional claims in published maps and institutional affiliations 